\title{
Hypertrichosis-acromegaloid facial appearance syndrome
}

INSERM

\section{Source}

INSERM. (1999). Orphanet: an online rare disease and orphan drug data base. Hypertrichosis-acromegaloid facial appearance syndrome. ORPHA:966

Hypertrichosis-acromegaloid facial appearance syndrome (HAFF) is a very rare multiple congenital abnormality syndrome manifesting from birth with progressive hypertrichosis congenita terminalis (thick scalp hair extending onto the forehead with generalized increased body hair) associated with a typical acromegaloid facial appearance (thick eyebrows, prominent supraorbital ridges, broad nasal bridge, anteverted nares, long and large philtrum, and prominent mouth with full lips) appearing during childhood. HAFF seems to belong to a spectrum of phenotypes with the clinically overlapping acromegaloid facial appearance syndrome and hypertrichotic osteochondrodysplasia, Cantù type (see these terms). 